\title{
Developmental expression of the endogenous TIMP gene and a TIMP-lacZ fusion gene in transgenic mice
}

\author{
Ann M. Flenniken and Bryan R.G. Williams ${ }^{1}$ \\ Division of Infectious Diseases, Research Institute, The Hospital for Sick Children and Department of Medical Genetics, \\ University of Toronto, Toronto, M5G 1X8 Canada
}

\begin{abstract}
We determined the expression pattern of the tissue inhibitor of metalloproteinase (TIMP) in the development of the mouse embryo using in situ hybridization and transgenesis. Localized TIMP RNA was first detected at 13.5 days post conceptus (p.c.) in tissues undergoing osteogenesis, such as the mandible, ribs, and calvaria. As development proceeded, TIMP RNA could be detected at additional sites, including the tooth buds, vertebrae, and long bones. To define the sequences regulating TIMP expression, we generated transgenic mice that expressed the Escherichia coli $\beta$-galactosidase gene under control of a 5 ' region of the mouse TIMP gene containing -2158 to -58 bp upstream of the initiator ATG. By use of an in situ assay for $\beta$-galactosidase activity, the TIMP-lacZ fusion gene product was localized to tissues that also expressed the endogenous TIMP gene, such as the mandible, calvaria, and vertebrae. The localization of TIMP to regions of intramembranous and endochondral bone is similar to that previously reported for TGF- $\beta$, a growth modulator believed to be involved in regulation of extracellular matrix (ECM) formation. Thus, the expression of TIMP in these regions is consistent with it playing a role in ECM deposition and turnover in development.
\end{abstract}

[Key Words: TIMP; RNA in situ; mouse development; bone; TIMP-lacZ fusion gene; $\beta$-gal in situ]

Received February 8, 1990; revised version accepted April 23, 1990.

The extracellular matrix (ECM) is a dynamic network of interacting proteins on the cell surface and consists of molecules such as collagen, fibronectin, laminin, and proteoglycans. Regulated turnover and remodeling of the components of the ECM are likely to be essential in controlling cell-ECM inductive interactions and morphogenesis of connective tissue structures such as skin, bone, tendon, and cartilage. Together, these processes are necessary for normal embryogenesis, growth, and maintenance of the developed state. Aberrant turnover of the ECM is thought to be the cause of such diseased states as the cartilage degradation associated with arthritis (Harris et al. 1984; Dean et al. 1989) and the invasion of tumor cells through basement membranes (Mignatti et al. 1986; Tryggvason et al. 1987).

The metalloproteinases, a multigene family of metaldependent proteinases, are believed to function as the rate-limiting enzymes in ECM degradation. These enzymes include collagenase, stromelysin, and gelatinase, and, together, are capable of degrading most of the components of the ECM. The local activity of these proteinases is regulated by the tissue inhibitor of metalloproteinases (TIMP) (Cawston et al. 1981; Murphy and Reynolds 1985). TIMP is a widely-distributed, secreted glycoprotein of $28.5 \mathrm{kD}$ (Welgus and Stricklin 1983)

${ }^{1}$ Corresponding author. that inhibits metalloproteinase activity by forming an irreversible complex with the enzyme in a $1: 1$ ratio (Cawston et al. 1983; Welgus et al. 1985).

Recently, in vitro studies have revealed that expression of metalloproteinases and TIMP is controlled by diverse extracellular stimuli including growth factors (Edwards et al. 1987; Overall et al. 1989), phorbol esters (Clark et al. 1985; Murphy et al. 1985; Angel et al. 1987), hormones (Sakyo et al. 1986), and virus (Gewert et al. 1987; Coulombe et al. 1988). In particular, one growth modulator, transforming growth factor- $\beta 1$ (TGF- $\beta 1$ ) has a selective reciprocal effect on metalloproteinase and TIMP expression. TGF- $\beta 1$ represses the induction of collagenase by growth factors such as basic fibroblast growth factor, but interacts cooperatively with these growth factors to superinduce TIMP expression (Edwards et al. 1987). The coregulation of metalloproteinases, such as collagenase, and TIMP by growth factors and growth modulators may function as an important regulator of ECM deposition and turnover in development.

To understand better how metalloproteinases and TIMP combine to regulate ECM turnover in vivo, it would be useful to map their pattern of expression in early development and to determine what controls this expression. This information will also help to identify diseases that may be associated with a defective TIMP 
gene structure or defective control of TIMP expression. Although TIMP has been regionally localized to the X chromosome in both mouse (Mullins et al. 1988) and human (Willard et al. 1989), the gene has not been linked directly to any known diseases.

Here we describe the temporal and spatial pattern of expression exhibited by the TIMP gene in early mouse development by use of in situ hybridization. We found TIMP expression was localized to areas undergoing deposition of large amounts of ECM. These included structures undergoing osteogenesis, such as the mandible, ribs, and long bones. To determine if appropriate spatial and temporal expression could be regulated by a discrete genomic fragment, we constructed several transgenic mouse lines that carry a fusion gene consisting of -2158 to $-58 \mathrm{bp}$ upstream of the initiator ATG fused to an indicator, the bacterial $l a c Z$ gene, encoding $\beta$-galactosidase activity. Thus, we were able to examine the expression of the fusion gene in all tissues at all stages of development. Our results indicate that this portion of the TIMP gene can direct expression of the lac $Z$ indicator gene in a pattern very similar to that seen for the endogenous TIMP gene.

\section{Results}

\section{Localization of TIMP gene expression during embryogenesis}

Expression of the endogenous TIMP gene in early mouse development was examined initially by Northern blot hybridization and RNase protection analyses. The 800to 900-base TIMP transcript was detectable by Northern blot analysis of poly $(\mathrm{A})^{+}$RNA isolated from control CD-1 embryos ranging in age from 13.5-18.5 days p.c. (Fig. 1A). By use of the method of RNase protection, TIMP mRNA could be detected as early as 9.5 days of gestation (Fig. 1B). On the basis of the relative intensity of the TIMP hybridization signal and that of the control probe, L27', the steady-state level of TIMP expression did not vary greatly at these stages (Fig. 1B).

In situ hybridization was used to examine the expression of the TIMP gene in sectioned embryos ranging in age from 8.5 to 17.5 days p.c. Although TIMP RNA was detected as early as 9.5 days p.c. by RNase protection analysis (Fig. 1B), localized TIMP expression was first seen at 13.5 days of gestation. At this stage, the hybridization signal was most intense in the mandible (Fig. 2B) but could also be detected around the clavicle, ribs, and femur (Fig. 2B) and in the calvaria (data not shown). Starting at 14.5 days p.c. and throughout the remainder of gestation, localized TIMP expression was found at the aforementioned sites and was also seen at sites such as the vertebrae (Fig. 2D,H), in the long bones of the upper and lower limbs (Fig. 2D,H), and in the bones of the pelvic girdle (Fig. $2 \mathrm{H}$ ). A control sense-strand probe gave background nonspecific hybridization that was distributed over the entire embryo and not localized to the tissues to which the antisense TIMP probe hybridized (Fig. 2F). The pattern of distribution of TIMP indicated that mRNA for this metalloproteinase inhibitor was

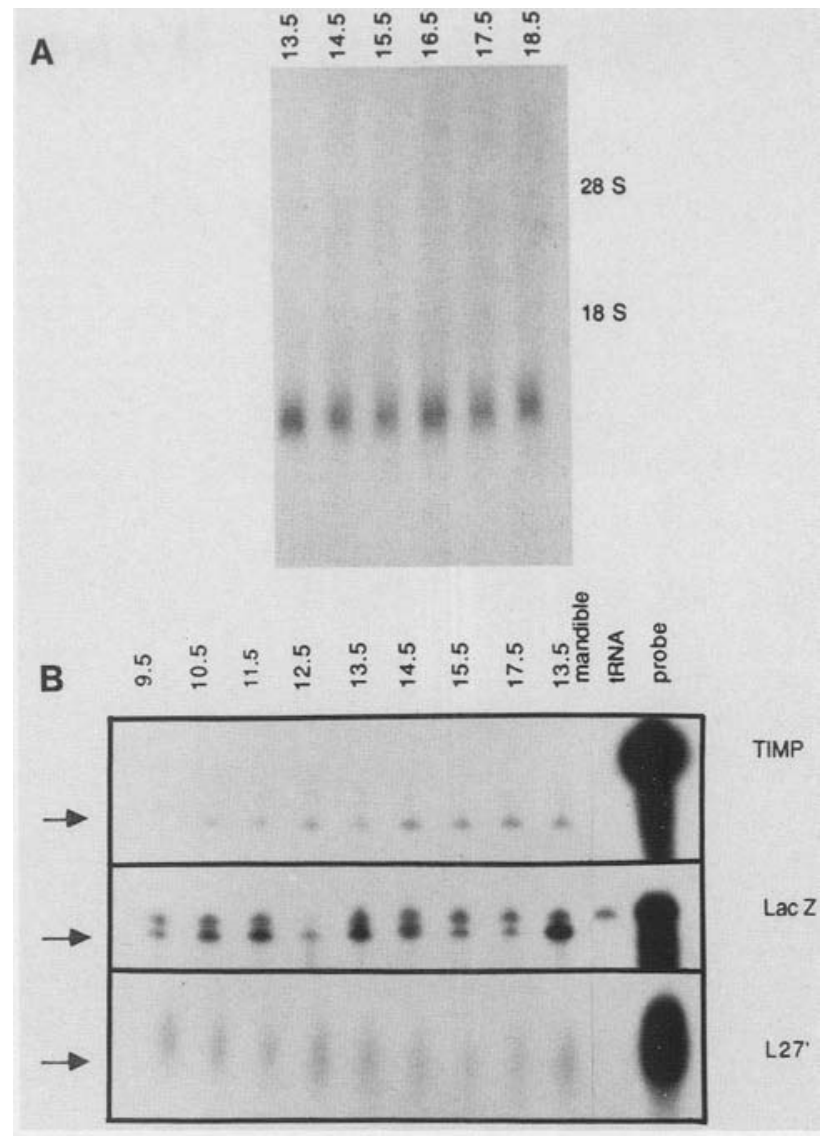

Figure 1. (A) Expression of the TIMP gene during embryogenesis. RNA was extracted from CD-1 embryos ranging in age from 13.5 to 18.5 days p.c. and analyzed by a Northem blot with poly $(\mathrm{A}){ }^{+}$RNA $(10 \mu \mathrm{g})$ hybridized to the mouse TIMP cDNA. $(B)$ Comparison of TIMP gene and TIMP-lacZ fusion gene expression during embryogenesis by RNase protection analysis. RNA was extracted from whole mouse embryos homozygous for the TIMP-lacZ fusion gene ranging in age from 9.5 to 17.5 days p.c. and from the 13.5-day p.c. mandible, as indicated at the top of each lane. The arrows indicate the positions of the protected probe fragments. Undigested probe is indicated in the far right lane.

found in areas of ossification during both intramembranous and endochondral bone formation.

To confirm that TIMP expression was associated with tissues undergoing ossification, embryo sections were stained with Alizarin Red S. Areas that contain deposited calcium, which is indicative of ossification, turn bright red when treated with this stain. A comparison of the tissues that expressed the TIMP gene at 14.5 days of gestation by in situ hybridization (Fig. 3B) to embryos of the same stage stained with Alizarin Red S (Fig. 3C) confirmed that these sites did represent the sites of ossification of the cranium, mandible, ribs, and femur.

The pattern of TIMP gene expression was examined in detail in both endochondral and intramembranous bone. Bones undergoing endochondral bone formation include the long bones of the limbs, the vertebral column, and the bones of the pelvic girdle. TIMP RNA was first de- 


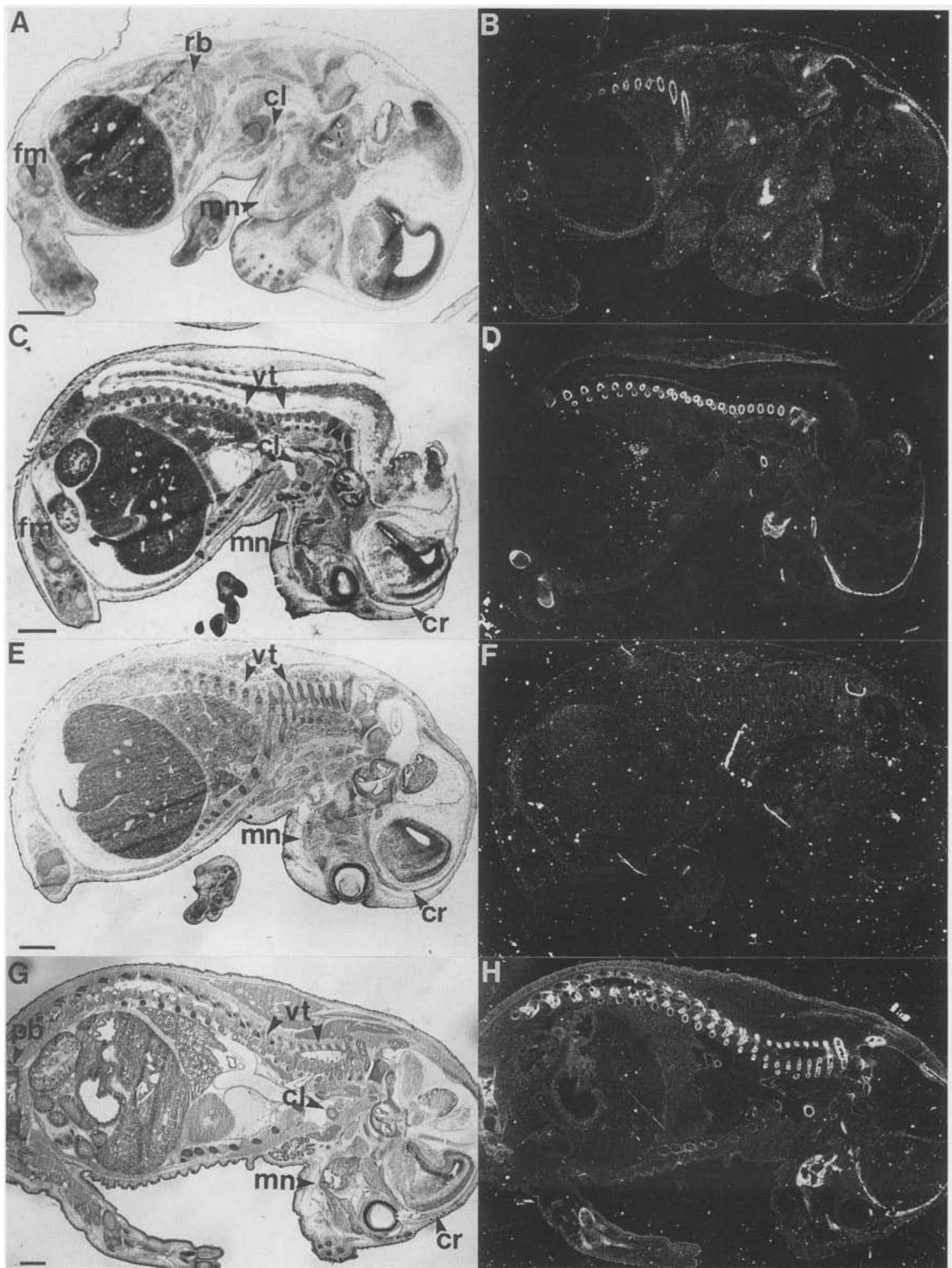

Figure 2. Localization of TIMP transcripts within sagittal sections of 13.5-, 15.5-, and 17.5-day p.c. embryos. Sections were photographed with bright-field illumination (left) to depict the morphology and with dark-field illumination (right) to show hybridization signals. $(A$ and $B)$ 13.5-day p.c. embryo. $(C$ and $D)$ 15.5-day p.c. embryo. ( $E$ and $F)$ 15.5-day p.c. embryo hybridized with the control sense engrailed-2 probe. ( $G$ and $H$ ) 17.5-day p.c. embryo. (cl) Clavicle; $(\mathrm{cr})$ cranium; (fm) femur; (mn) mandible; (pb) pelvic bone; (rb) ribs; (vt) vertebrae. Bars, $1 \mathrm{~mm}$. 

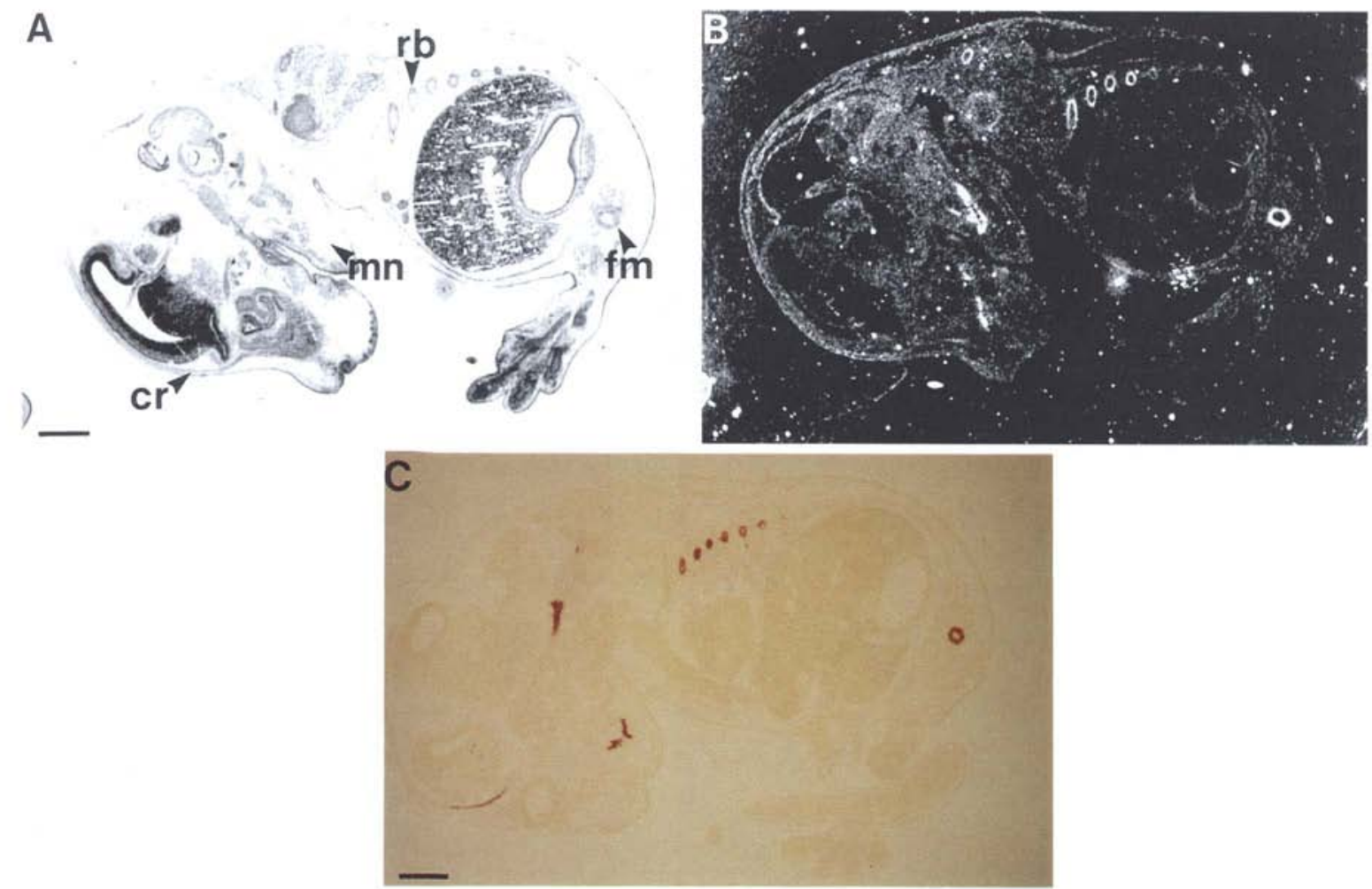

Figure 3. Comparison of TIMP gene expression to the distribution of deposited calcium in the 14.5-day p.c. embryo. Sections were photographed using bright-field illumination (left) to depict the morphology and using dark-field illumination (right) to show hybridization signals. $(A$ and $B)$ Sagittal section of the embryo hybridized with the antisense TIMP probe. $(C)$ Similar section after Alizarin Red S staining. Calcium deposition is indicated by the bright red color. (cr) Cranium; $(\mathrm{fm})$ femur; $(\mathrm{mn})$ mandible; $(\mathrm{rb})$ ribs. Bars, $1 \mathrm{~mm}$.

tected around the ribs of the 13.5-day p.c. embryo (Fig. 2B) and was localized to the ring of cells and ECM surrounding the cartilaginous core (Fig. 4B). At this stage, no signal could be seen in the developing vertebrae. At 14.5 days p.c., TIMP expression was restricted to the periphery of the cervical vertebrae. The cervical vertebrae undergo ossification before the rest of the vertebrae because the anterior axial skeleton develops earlier than the caudal skeleton. By 15.5 days p.c., TIMP expression spanned almost the entire length of the vertebral column and was found both around the vertebral arches and in the vertebral bodies (Fig. 2D). In the 17.5-day p.c. embryo, a hybridization signal was seen around the periphery of the vertebral body at sites of ECM deposition and within the central region of the body (Fig. 4D). No expression was seen in the intervertebral discs located on each side of the vertebral bodies (Fig. 4D).

In the long bones of the embryo, faint expression was first detected around the femur at 13.5 days p.c. (Fig. 2B) and this signal became more intense at 14.5 days p.c. (Fig. 3B). As development progressed, TIMP RNA could be found around all of the bones of the upper and lower limbs, and in the bones of the pelvic girdle (Fig. 2D,H). The humerus of a 15.5-day p.c. embryo was examined to determine expression in a developing long bone undergoing endochondral ossification. TIMP expression was detected in the periosteal collar around the cartilage model and in the region of the primary marrow cavity (Fig. 4F). This expression was restricted to the site of new endochondral bone formation within the cartilage model and was not detected in either the hypertrophic cartilage adjacent to the bone or in the more distal areas of proliferating and resting cartilage (Fig. 4F). In the metatarsal of the 17.5-day p.c. embryo, an intense TIMP RNA signal was localized to the ossification collar in the mid-diaphyseal region of the bone (Fig. 4H).

Bones undergoing intramembranous bone formation include the bones of the skull, mandible, and maxilla. It is in these bones that high levels of TIMP expression were first detected at 13.5 days p.c.. At this stage, TIMP expression was restricted to a small area of ECM deposition in the mandible (Fig. 7B, below). As development proceeded to 17.5 days p.c., the areas of expression expanded with the growth of the mandible and continued in areas forming alveolar bone (Fig. 7E, below). In the maxillary bone, TIMP gene expression was first detected at 15.5 days p.c. and more intensely at 17.5 days p.c. as illustrated in the alveolar bone supporting the upper incisor (Fig. 5B). A high level of TIMP RNA was also detected in the intramembranous bones of the skull beginning at 13.5 days p.c. A comparable signal intensity was maintained along the length of the ossifying plates 


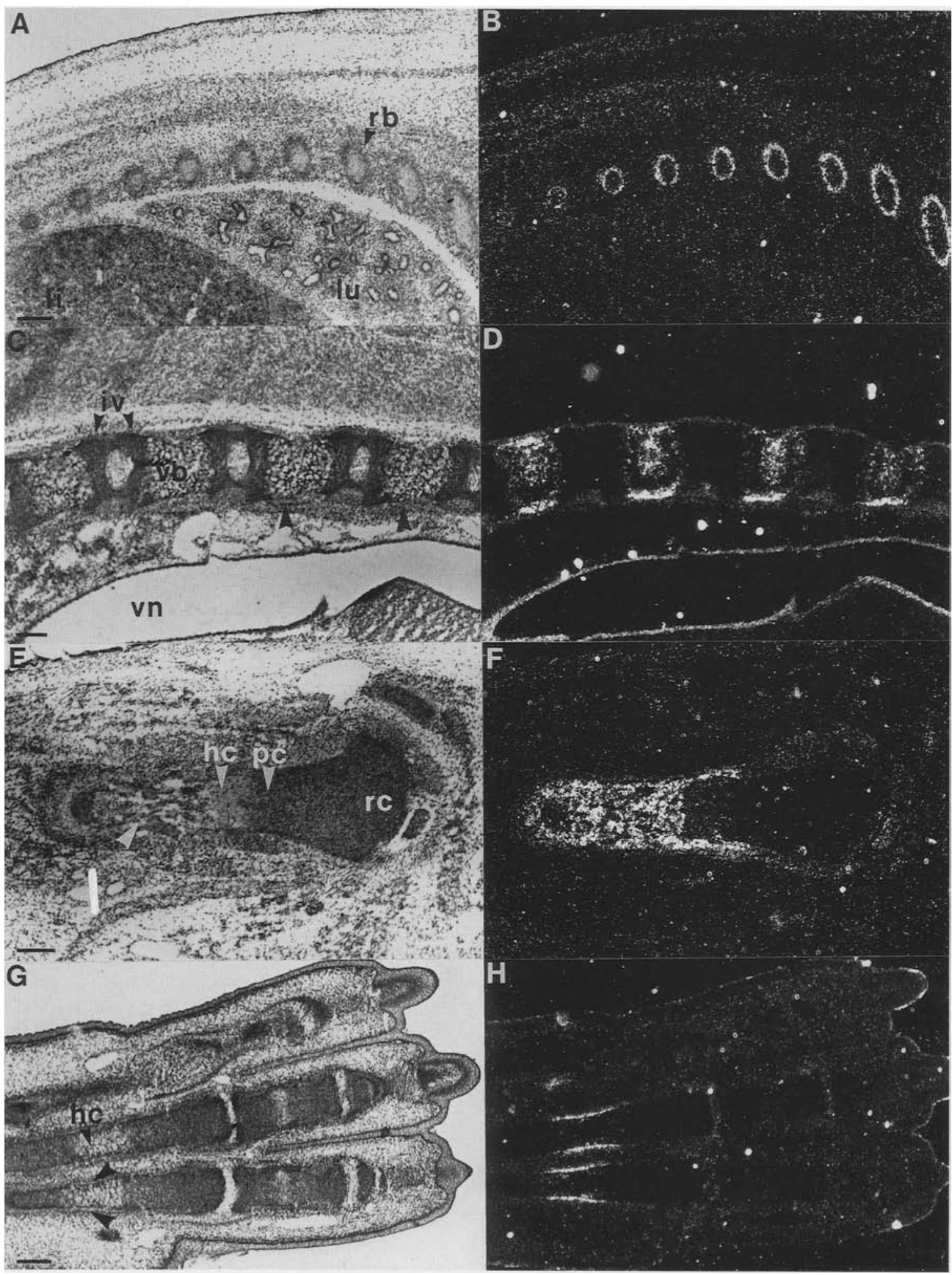

Figure 4. TIMP RNA distribution in various ossifying tissues. Sections were photographed using bright-field illumination (left) to depict the morphology and using dark-field illumination (right) to show hybridization signals. $(A$ and $B)$ Sagittal section of the ribs of a 13.5-day p.c. embryo. $\{C$ and $D\}$ Midsagittal section of a 17.5-day p.c. vertebral column. Arrowheads indicate ECM deposition along the vertebral bodies. ( $E$ and $F$ ) Frontal section of a 15.5-day p.c. humerus. Arrowhead indicates area of endochondral bone formation. $(G$ and $H)$ Frontal section of a 17.5-day p.c. hindfoot. Arrowheads indicate the primary ossification collar around the hypertrophic cartilage of the metatarsal. (hc) Hypertrophic cartilage; (iv) intervertebral disc; (li) liver; (lu) lung; (pc) proliferating cartilage; (rb) ribs; (rc) resting cartilage; (vb) vertebral body; (vn) vein. Bars, $200 \mu \mathrm{m}$. 
throughout the gestational time examined (Fig. $7 \mathrm{H}$, below). As development proceeded, expression could also be detected around the bones at the base of the skull such as the exoccipital and basisphenoid bones (data not shown). Other flat bones that exhibited TIMP gene expression were the scapula and the sternum.

The clavicle is one of the earliest ossifying bones of the embryo and undergoes a combination of intramembranous followed by cartilaginous bone formation. An intense hybridization signal was seen starting at 13.5 days p.c. that continued throughout gestation. Silver grains appeared to be localized to the layer of cells that surround the core of cartilage (Fig. $7 \mathrm{~K}$, below).

TIMP expression could not be detected in the devel- oping upper and lower incisors of the 15.5-day p.c. embryo. However by 17.5 days p.c., localized expression could be seen clearly. In the less developed upper incisor of the 17.5-day p.c. embryo (the upper incisor can develop as much as $12-24 \mathrm{hr}$ behind the lower incisor; Rugh 1968), TIMP gene expression was found uniformly distributed over the entire dental papilla (Fig. 5B). No expression was seen in the cells of the enamel organ consisting of the outer and inner enamel epithelia and the intervening stellate reticulum (Fig. 5B). In the further developed lower incisor, the ring of odontoblasts could be distinguished on the inner face of the dentin layer (Fig. 5F). TIMP expression was high over the odontoblasts and was also found scattered throughout the

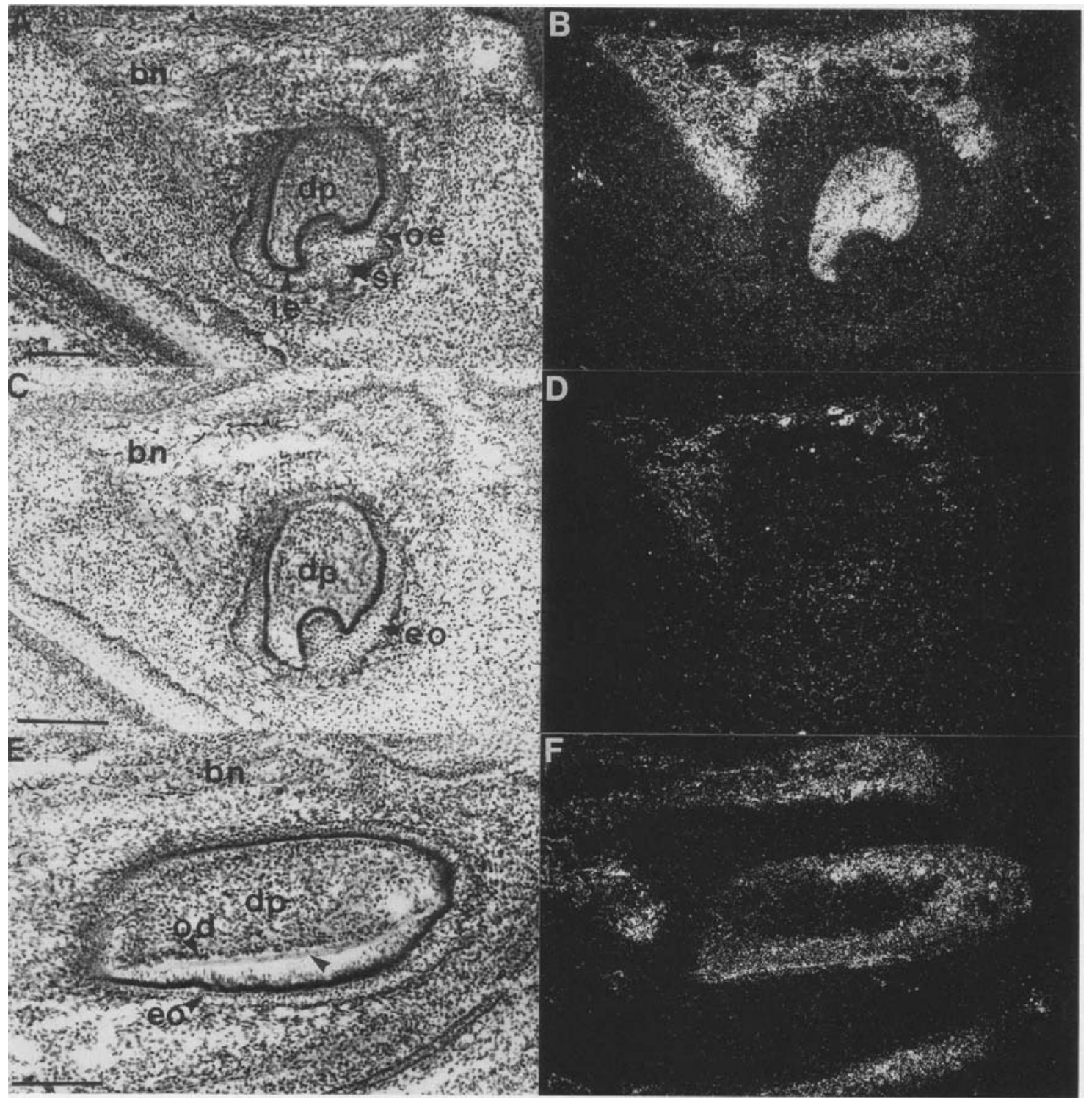

Figure 5. Localization of TIMP transcripts in sagittal sections of 17.5-day p.c. tooth buds. Sections were photographed using brightfield illumination (left) to depict the morphology and using dark-field illumination (right) to show hybridization signals. $(A$ and $B$ ) Upper incisor. $(C$ and $D)$ Upper incisor probed with the control sense TIMP probe. $(E$ and $F\rangle$ Lower incisor. The arrowhead indicates the layer of dentin. (bn) Bone; (dp) dental papilla; (eo) enamel organ; (ie) inner enamel epithelium; (od) odontoblasts; (oe) outer enamel epithelium; (sr) stellate reticulum. Bars, $200 \mu \mathrm{m}$. 
central region of the dental papilla. As with the upper incisor, no signal could be seen in the cells of the enamel organ (Fig. 5F). A control sense probe gave background, that is, nonspecific hybridization that was distributed over the entire tooth bud (Fig. 5D).

\section{Generation of TIMP-lacZ transgenic mice}

To define sequences responsible for regulating localized TIMP expression we constructed a TIMP-lac $Z$ fusion gene comprised of the putative TIMP promoter of the mouse fused to the coding sequences of an Escherichia coli gpt-trpS-lacZ fusion gene (Hall et al. 1983) (Fig. 6). Initially, several fusion genes were constructed containing varying amounts of TIMP sequence upstream of the initiator ATG fused to the lacZ gene. These constructs were transfected into NIH-3T3 cells and $\beta$-galactosidase activity was measured in cells treated with and without the phorbol ester, TPA (data not shown). The smallest, TPA-inducible construct contained the TIMP sequences -2158 to -58 relative to the ATG, and this was used for the transgenesis experiments. The 6-kb PstI fragment containing the TIMP-lacZ fusion gene was excised from the plasmid and microinjected into fertilized mouse eggs. Of 256 embryos transferred to pseudopregnant foster mothers, 58 mice were born. Southern blot analysis of DNA from tail biopsies revealed that six mice carried the transgene. Outcrossing of these founder transgenic animals to $\mathrm{CD}-1$ mice indicated that five of the six mice carried germ line integrations. Restriction enzyme analysis of DNA from these mice demonstrated that all lines carried unrearranged fusion genes ranging in copy number from $\sim 3-30$ (Fig. 6).

\section{Comparison of endogenous TIMP gene and TIMP-lacZ transgene expressions}

The expression of the TIMP-lac $Z$ fusion gene was detected initially by use of RNase protection assays. This analysis showed lacZ message in total RNA isolated from homozygous embryos derived from two founders, Line 1 and Line 2. The level of lacZ transcript was much higher in embryos of Line 2 than Line 1, therefore, homozygous embryos of Line 2 were used for the studies described below. In these transgenic embryos, the lacZ message could be detected at 9.5 days p.c. and throughout gestation, as seen with the endogenous TIMP gene (Fig. 1B). Total RNA was also prepared from the mandible, which was dissected from the head of a 13.5-day p.c. embryo. Both the endogenous TIMP mRNA and that of the TIMP-lacZ fusion gene could be detected in this tissue by RNase protection (Fig. 1B).

The expression of the TIMP-lacZ fusion gene was also analyzed by in situ $\beta$-galactosidase activity. This allowed a comparison of the temporal and spatial expression of the transgene and the endogenous TIMP gene. Although RNA analyses indicated that two of the transgenic lines expressed the transgene, expression of the $\beta$ galactosidase enzyme in situ could be detected in only one of the five transgenic mice lines. Detection of the

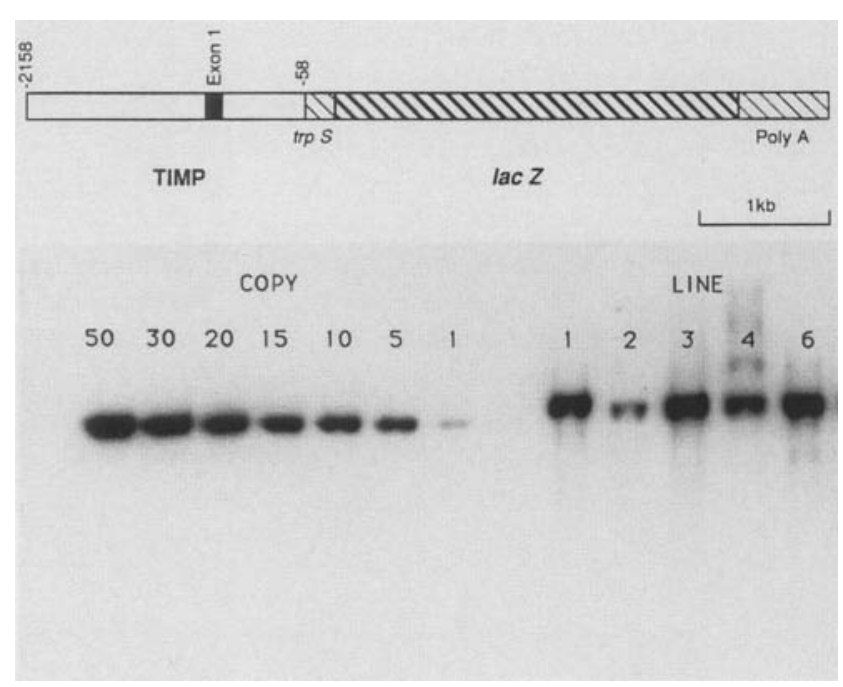

Figure 6. Structure of the mouse TIMP-lacZ fusion gene construct. The 6-kb PstI fragment was microinjected into fertilized eggs. The hybrid gene consisted of sequences -2158 to $-58 \mathrm{bp}$ upstream of the translational start site of the putative TIMP promoter [open area with solid area representing the nontranslated exon 1 (Coulombe et al. 1988)], the E. coli gpt-trpS-lacZ fusion gene (light and dark stripe), and the SV40 polyadenylation signal (light stripe). The TIMP-lacZ fusion gene was detected by Southern blot analysis. DNA extracted from the 5 transgenic lines was digested with HindIII-BamHI. The 3.4-kb HindIII-BamHI fragment spanning the $l a c Z$ fusion gene was used as a probe and to determine the copy number integrated in each line.

blue precipitate indicative of $\beta$-galactosidase activity was difficult under bright-field illumination. However, when viewed under dark-field illumination, the blue granules were pink in color, which was easier to discern against a dark background (Gossler et al. 1989). No background $\beta$-galactosidase activity could be detected in control CD-1 embryos.

A comparison of the expression patterns of the endogenous TIMP gene to that of the TIMP-lac $Z$ fusion gene in the intramembranous bones indicated that both were regulated in a similar temporal and tissue-specific manner. Localized $\beta$-galactosidase activity was detected first in the mandible of the 13.5-day p.c. embryo. Activity appeared highest in the mandible at a site undergoing ECM deposition in accordance with expression of the endogenous TIMP gene at this stage (Fig. $7 \mathrm{C}$ ). As development proceeded to 17.5 days p.c., $\beta$-galactosidase activity increased to encompass the enlarging ossifying mandible (Fig. 7F). Within the lower jaw, the specialized band of cartilage known as Meckel's cartilage around which alveolar bone first forms, expressed both the endogenous TIMP gene and the TIMP-lacZ fusion gene (Fig. 7E,F). Expression of lac $Z$ was also observed in ossifying tissue in the maxilla at this stage (data not shown). In the intramembranous bones of the skull, pink granules indicative of $\beta$-galactosidase activity could be detected in the ossifying plates in a similar location to 


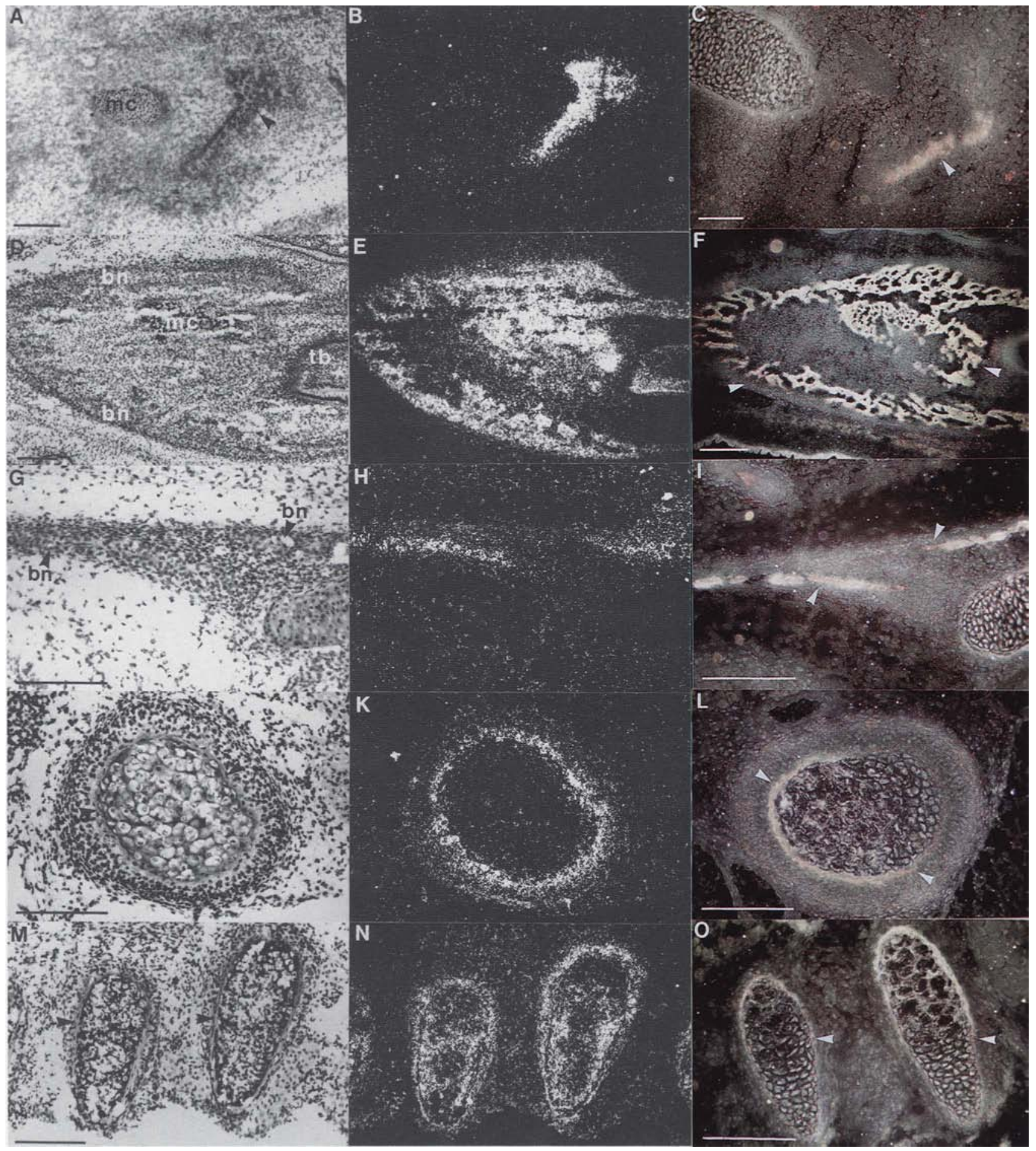

Figure 7. Comparison of TIMP and TIMP-lacZ fusion gene expression in sagittal sections of tissues from transgenic embryos. Sections were hybridized with the TIMP antisense probe and photographed under bright-field (left) and dark-field (middle) illumination. Similar sections were assayed for $\beta$-galactosidase activity (pink granules) and photographed under dark-field illumination (right). $(A, B$, and $C) 13.5$-day p.c. mandible. $(D, E$, and $F) 17.5$-day p.c. mandible. $(G, H$, and $I) 17.5$-day p.c. calvaria. $(J, K$, and $L) 17.5$-day p.c. clavicle. $(M, N$, and $O)$ 17.5-day p.c. cervical vertebrae. (bn) Bone; $(\mathrm{mc}) \mathrm{Meckel}^{\prime}$ cartilage; (tb) tooth bud. Arrowheads in the left panel indicate areas of ECM deposition and arrowheads in the right panel indicate areas with pink granules. Bars, $200 \mu \mathrm{m}$. 
that observed with in situ hybridization using the endogenous TIMP gene (Fig. $7 \mathrm{H}, \mathrm{I}$ ).

A comparison of endogenous TIMP gene and transgene expression in the developing clavicle indicated that the deposition of both silver grains and pink granules was highest in the region of ECM immediately adjacent to the cartilaginous core (Fig. $7 \mathrm{~K}, \mathrm{~L}$ ). Less intense expression of both genes was scattered over the more peripheral osteoblastlike cells.

Expression of the TIMP-lacZ fusion gene product could also be detected in bones undergoing endochondral ossification. For example, a fine layer of pink granules could be seen deposited on the ECM surrounding the cartilaginous core of the cervical vertebrae of a 17.5-day p.c. embryo (Fig. 7O). Again, localization of fusion gene expression corresponded well to that observed with the endogenous gene (Fig. $7 \mathrm{~N}$ ). In the pelvic girdle of an embryo of the same stage, $\beta$-galactosidase activity was found in newly formed endochondral bone and in the peripheral layer of loose fibrous connective tissue that demarcates the developing bone (data not shown).

In the developing tooth bud of a 17.5-day p.c. embryo, a low level of lacZ expression was detected in the central region of the dental papilla and over the odontoblasts (data not shown), which are both structures that expressed the endogenous TIMP gene.

\section{Unique lacZ expression}

Expression of the TIMP-lac $Z$ fusion gene was detected in some areas where TIMP expression could not be detected above background hybridization levels in the in situ hybridization analysis. For example, high $\beta$-galactosidase activity was detected in the root sheath of the hair follicles that form the vibrissae (whiskers) of the snout (Fig. 8A). Expression in this region could not be detected at 13.5 days p.c. but could be seen at 14.5 days of gestation. This $\beta$-galactosidase activity continued throughout gestation to adulthood where expression could also be seen in hair follicles such as those of the ear and tail (data not shown). Pink granules were also seen scattered in the mesenchyme tissue of the snout (Fig. 8A). Connective tissue of the tongue but not the overlying epithelium, also showed expression of the TIMP-IacZ fusion gene (Fig. 8B). A low level of $\beta$-galactosidase activity was also detected over the stellate reticulum in both the upper and lower incisors.

\section{Discussion}

Using a combination of Northern blot hybridization and RNase protection analyses, we detected TIMP RNA in whole-mouse embryos as early as 9.5 days p.c. Examination of TIMP expression by in situ hybridization of embryos ranging in age from 8.5 to 17.5 days p.c. revealed that localized TIMP expression was not detected until 13.5 days of gestation. The fact that TIMP localization was not detected until 13.5 days p.c., even though TIMP message could be detected much earlier, may be a function of the sensitivity of the in situ hybridization assay. It is possible that the TIMP mRNA detected earlier in development is distributed evenly throughout the embryo or that signals occurring at specific sites are such that they are lost beneath the background of the assay. It is conceivable that widespread, low levels of TIMP gene expression are necessary to maintain the integrity of the ECM that exists over the entire body, whereas higher levels are necessary in localized areas during periods of rapid ECM deposition.

Tissues in which localized expression of TIMP could be detected were those undergoing ossification, such as intramembranous and endochondral bone. More specifically, TIMP appeared to be expressed directly in the ECM and in the cells immediately adjacent to the ECM, which are probably responsible for deposition of this material. For example, at 13.5 days of gestation, TIMP expression was found in the ECM deposited in a small area of the mandible. This observation was confirmed by RNase protection analysis of total RNA extracted from the isolated mandible. Other tissues that undergo ECM deposition are the calvaria, ribs, and clavicle. These areas were verified as areas of ossification and calcium deposition in early development using the stain Alizarin

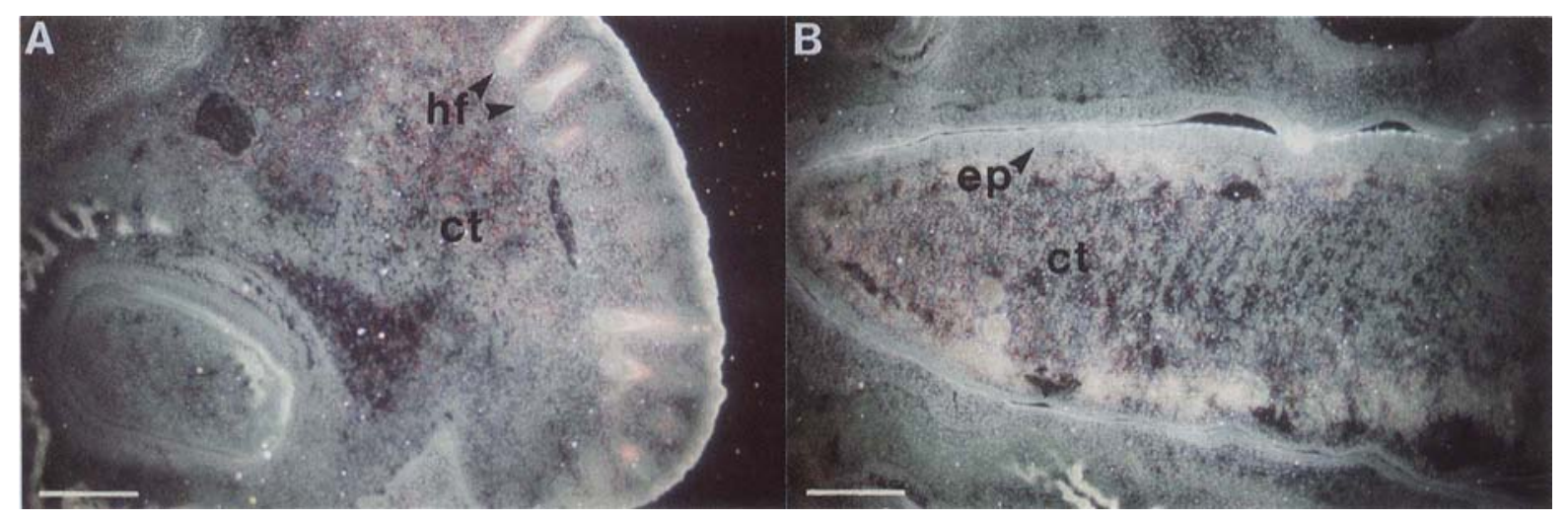

Figure 8. Unique TIMP-lacZ fusion gene expression in 17.5-day p.c. embryos. Pink granules indicate $\beta$-galactosidase activity. $(A)$ Sagittal section of the snout. $(B)$ Sagittal section of the tongue. (ep) Epithelium; (hf) hair follicles; (ct) connective tissue. Bars, $200 \mu \mathrm{m}$. 
Red S. As development proceeded to 17.5 days of gestation, TIMP gene expression was found in the majority of ossifying tissues including the vertebrae, the long bones of the upper and lower limbs, and the bones of the pelvic girdle. During osteogenesis and modeling of these tissues, TIMP likely functions to protect newly deposited ECM and to help maintain the balance between ECM deposition and degradation and turnover. Recently, Nomura et al. (1989) showed localization of TIMP to osteogenic tissue in the head and limb of the mouse embryo commencing at about 15.5 days p.c. The earlier detection of hybridization reported here could be due to differences in methodology. In our study, frozen sections were used, whereas Nomura et al. (1989) used embryos that were embedded in paraffin. Overall, however, the findings of the two studies were in accordance with localized TIMP expression in ossifying tissues.

TIMP expression was also found in the developing upper and lower incisors. During development of the tooth, a thickening of the oral epithelium, called the dental lamina, elongates and forms a cap-shaped layer of epithelium that forms the enamel organ. The enamel organ consists of the outer enamel epithelium, the intervening stellate reticulum, and the inner enamel epithelium. The outer and inner enamel epithelia surround a core of cells, called the dental papilla, that arises from the condensation of mesenchymal tissue in the upper and lower jaw. The outer layer of the dental papilla differentiates into odontoblasts, whereas the central region of the dental papilla remains as a core of connective tissue (Leeson et al. 1985; Rugh 1968). TIMP RNA was localized to the dental papilla and odontoblasts. This observation is consistent with TIMP involvement in protecting newly synthesized ECM because it is these tissues that are responsible for producing the collagen fibers and mucopolysaccharides upon which deposition of mineral occurs to form dentin (Leeson et al. 1985).

It is of interest to note that TIMP expression was localized to many of the same tissues in which TGF- $\beta$ expression has been detected. Both immunohistochemical staining (Heine et al. 1987) and in situ hybridization studies have localized TGF- $\beta 1$ to intramembranous bone such as that of the calvaria (Heine et al. 1987; Lehnert and Akhurst 1988) and to the mid-diaphyseal region of the newly forming endochondral bone in both mouse (Heine et al. 1987; Carrington et al. 1988) and human (Sandberg et al. 1988). Another member of the TGF- $\beta$ superfamily, TGF- $\beta 2$, has also been localized to the developing long bone in the central region of the bone as well as in the surrounding periosteal layer (Pelton et al. 1989 |. TGF- $\beta 2$ is also found within the developing mandible, maxilla, and calvaria.

In vitro studies of fibroblasts have shown that TGF- $\beta 1$ causes an increased expression of the major ECM components, collagen and fibronectin, and also stimulates their incorporation into the ECM (Ignotz and Massague 1986). Moreover, TGF- $\beta 1$ induces TIMP production while reciprocally reducing collagenase production (Edwards et al. 1987). These data and the location of TIMP expression in the developing mouse embryo allow us to speculate on one possible functional interaction of TIMP and TGF- $\beta$ expression in vivo. In the developing mouse embryo, the TGF- $\beta$ superfamily may function in concert with other growth factors to produce ECM by inducing collagen and fibronectin synthesis and may also maintain the integrity of newly synthesized ECM by inducing TIMP production while at the same time inhibiting collagenase synthesis. It is important to note that although TGF- $\beta$ is a likely candidate for control of TIMP expression in vivo, it is also found in many tissues in which TIMP has not been localized by in situ hybridization such as dermis and intervertebral discs (Heine et al. 1987).

To determine if specific sequences upstream of the TIMP ATG could control temporal and tissue-specific expression of the TIMP gene, a fusion gene was constructed that consisted of $2101 \mathrm{bp}$ of putative TIMP promoter sequences fused to the bacterial $1 a c Z$ indicator gene. By use of an in situ assay for $\beta$-galactosidase activity, the TIMP-lacZ fusion gene was found to be expressed in similar places to the endogenous TIMP gene, that is, in tissues undergoing ECM deposition and ossification. Deposition of the insoluble dye resulting from $\beta$-galactosidase activity appeared highest in locations in and surrounding areas of high ECM deposition such as in the mandible and around the clavicle and cervical vertebrae. Localized expression was seen first in the mandible of a 13.5-day p.c. embryo, which is where an intense endogenous TIMP signal was detected first. In general, $\beta$ galactosidase activity was detected more easily in bones undergoing intramembranous ossification such as the mandible and calvaria than in the endochondral bones such as the vertebrae and bones of the pelvic girdle. This observation is consistent with results obtained with the endogenous TIMP gene because the most intense signals detected by in situ hybridization were also in the intramembranous bones. Therefore, we suggest that the sequences -2158 to $-58 \mathrm{bp}$ upstream of the translational start site likely contain the regulatory elements necessary to control the correct temporal and spatial expression of the fusion gene. Recently, we identified a 30-bp element $(-858$ to -829 with respect to the initiating ATG) that is responsive to serum, phorbol ester, and TGF- $\beta 1$ induction (C. Campbell, A. Flenniken, and B. Williams, unpubl.). The TIMP-IacZ fusion gene contains this sequence and also contains the first intron of the TIMP gene, which we have shown previously to contain the virus-responsive elements (Coulombe et al. 1988).

There are some locations, such as the root sheath of the whiskers, in which the transgene is easily detected but the endogenous TIMP gene is not. This result could be a function of the differing sensitivities of the techniques or stability of the products measured because the in situ $\beta$-galactosidase technique detects protein activity while in situ hybridization detects the presence of mRNA. In fact, TIMP expression has been detected by Northern blot hybridization in RNA extracted from isolated whiskers of a 3-day neonate mouse (V. Groppi, pers. comm.). Interestingly, the additional sites at which 
$\beta$-galactosidase activity was detected, such as the whiskers, the connective tissue of the snout and tongue, and the stellate reticulum of the tooth bud are all structures in which TGF- $\beta 1$ expression has been found. It is also interesting to note that another member of the TGF- $\beta$ family, TGF- $\beta 2$, and a TGF- $\beta 1$-regulated gene, SPARC (osteonectin), are similarly expressed in the root sheath of the whiskers (Holland et al. 1987; Heine et al. 1987; Pelton et al. 1989).

The localization of the mouse TIMP RNA to regions of intramembranous and endochondral bone is consistent with TIMP playing a role in ECM deposition and turnover in development. A comparison of this expression pattern to that of the metalloproteinases that are inhibited by TIMP, such as collagenase and stromelysin, will enable a better understanding of their coordinate function in the formation and maintenance of the architectural stability of the ECM. By the method of transgenesis, it has been established that the regulatory sequences necessary for normal temporal and spatial expression of the mouse TIMP gene lie within an $\sim 2100$-bp stretch upstream of the initiator ATG. Furthermore, with the identification of the 30 -bp element within this promoter region that is inducible by treatment with growth factor and phorbol ester (Campbell et al., unpubl.), it should now be possible to use transgenesis or homologous recombination to alter TIMP gene expression subtly and establish its role in normal development.

\section{Materials and methods \\ Embryo collection}

Embryos were recovered at various stages of post-implantation development. Noon on the day of the vaginal plug was designated 0.5 days p.c. Embryos were collected in sterile phosphate-buffered saline (PBS) and dissected away from all membranes. For in situ analyses, embryos were frozen in OCT medium (Tissue-Tek) and sectioned at $7-10 \mu \mathrm{m}$ on a cryostat microtome. To prepare RNA, embryos were disrupted by Dounce homogenization in guanidinium thiocyanate and RNA recovered following centrifugation over cesium chloride according to the method of Chirgwin et al. (1979). Poly(A) ${ }^{+}$RNA was prepared essentially as described in Maniatis et al. (1982).

\section{Northern blot and RNase protection assays}

RNA analysis by Northern blot hybridization was performed as described previously by Flenniken et al. (1988). TIMP RNA was detected by use of the mouse TIMP cDNA /Coulombe and Skup 1988; kindly provided by D. Skup). lacZ RNA was detected using the $3.4-\mathrm{kb}$ HindIII-BamHI fragment encoding the bacterial lacZ gene, which was excised from the vector $\mathrm{pCH} 126$, a derivative of pCH110 (Hall et al. 1983). DNA was radioactively labeled with $\left[\alpha^{-32} \mathrm{P}\right] \mathrm{dATP}$ (New England Nuclear) by the method of random priming (Feinberg and Vogelstein 1983).

RNase protection assays were performed as described by Dunn et al. (1988). All determinations were made on the same RNA samples extracted from transgenic embryos of various ages. The 160-bp PstI-AvaII fragment of the mouse TIMP cDNA was subcloned into the vector pGEM-3 (Promega). Antisense RNA was synthesized using SP6 polymerase after linearization with BamHI (Melton et al. 1984). The 360-bp PvuII frag- ment of the bacterial $1 a c Z$ gene was subcloned into pGEM-4 (Promega) and antisense RNA prepared using SP6 polymerase after linearization with BamHI. A 60-base antisense $\mathrm{L} 27^{\prime}$ probe (Belhumeur et al. 1987; provided by D. Skup) was synthesized using SP6 polymerase after linearizing the clone in pGEM-1 (Promega) with BanI. The probes were hybridized to $20 \mu \mathrm{g}$ of total RNA isolated from various mouse tissues. Calf liver tRNA $(20 \mu \mathrm{g})$ was included in all assays to identify nonspecific bands. Hybridizations were carried out at $50^{\circ} \mathrm{C}$ for $\sim 18 \mathrm{hr}$ using $1-2 \times 10^{5} \mathrm{cpm}$ of the TIMP and lacZ probes and $1 \times 10^{4} \mathrm{cpm}$ of the L27' probe. Protected fragments were analyzed on a $5 \%$ polyacrylamide/urea gel and detected by autoradiography. Sizes of the protected fragments were confirmed by comparison to RNA markers provided by the Promega Riboprobe System (Promega).

\section{In situ hybridization}

In situ hybridization was performed as described by Davis et al. (1988). Sectioned embryos were fixed, acetylated, dried through an ethanol series and stored dessicated at $-70^{\circ} \mathrm{C}$. RNA probes were labeled with $\left[{ }^{35} \mathrm{~S}\right] \mathrm{UTP}$ (Amersham, $410 \mathrm{Ci} / \mathrm{mmole}$ ). The antisense TIMP RNA probe was prepared using the PstI-AvaII fragment of the mouse TIMP cDNA. Two sense control probes were generated from the mouse TIMP cDNA: a 160-base RNA generated from the PstI-AvaII fragment and a 300-base RNA generated from the StuI-PstI fragment. A nonrelated sense control probe was also used and generated using the 260 bp BgIII-SstI fragment of the mouse engrailed-2 cDNA (Davis et al. 1988). Following hybridization and washing, slides were dipped in NTB-2 emulsion (Kodak) and exposed at $-70^{\circ} \mathrm{C}$ for 4-5 weeks.

\section{Alizarin Red S staining}

Embryos at 14.5 days p.c. were sectioned on the cryostat at 10 $\mu \mathrm{m}$ and loaded onto poly-L-lysine-coated slides. Sections were air-dried, fixed for $30 \mathrm{sec}$ in $10 \%$ formaldehyde and then dehydrated through an ethanol series. Slides were submerged in Alizarin Red S staining solution (pH 4.1), dehydrated in acetone, and mounted in Permount according to the method of McGeeRussell (1958). Sites of calcium deposition show a heavy red precipitate, whereas background tissues stain faint pink.

\section{Generation of transgenic mice}

Outbred CD-1 mice (Charles River, Canada) were used to generate transgenic mice. The 6-kb TIMP-lacZ fusion gene was microinjected into fertilized eggs as described by Kothary et al. (1989). Transgenic mice were identified at 3 weeks of age by Southern blot analysis of tail DNA (Southern 1975; Hogan et al. $1986)$ and by in situ detection of $\beta$-galactosidase activity. On the basis of these assays, mice carrying a germ line integration were identified and used to establish homozygous transgenic lines.

\section{E. coli $\beta$-galactosidase assay}

A histochemical staining procedure for $\beta$-galactosidase activity was used essentially as described by Dannenberg and Suga (1981). Mouse embryos of varying stages of development were frozen in OCT medium. Embryos were cut into $10 \mu \mathrm{m}$-thick sections and loaded on poly-L-lysine coated slides. After $1-3 \mathrm{hr}$ of air drying, sections were fixed in $0.5 \%$ glutaraldehyde in 0.1 M phosphate buffer ( $\mathrm{pH} 7.3$ ) at room temperature for $2 \mathrm{~min}$ and rinsed in phosphate buffer alone. Sections were submerged in 
$0.1 \mathrm{M}$ phosphate buffer $(\mathrm{pH} 7.3)$ containing $0.04 \%$ 4-chloro-5bromo-3-indolyl- $\beta$-D-galactopyranoside (X-gal, Sigma), $0.2 \mathrm{~mm}$ $\mathrm{NaCl}, 10 \mathrm{~mm}$-potassium ferrocyanide, and $10 \mathrm{~mm}$-potassium ferricyanide. Incubation was carried out for $12-36 \mathrm{hr}$ at $37^{\circ} \mathrm{C}$. Sections were counterstained with eosin (BDH Chemicals), dehydrated, and mounted in Permount (Fisher Scientific).

\section{Acknowledgments}

We thank Drs. Chris E. Campbell and Dan Skup for helpful discussions; Susan Clapoff for microinjection of the transgene; Clay Davis for advice with the in situ hybridization; and Nomi Pittel for Alizarin Red S staining. This work was supported by a grant from the Medical Research Council of Canada to B.R.G.W.

The publication costs of this article were defrayed in part by payment of page charges. This article must therefore be hereby marked "advertisement" in accordance with 18 USC section 1734 solely to indicate this fact.

\section{References}

Angel, P., M. Imagawa, R. Chiu, B. Stein, R.J. Imbra, H.J. Rahmsdorf, C. Jonat, P. Herrlich, and M. Karin. 1987. Phorbol ester-inducible genes contain a common cis element recognized by a TPA-modulated trans-acting factor. Cell 49: 729-739.

Belhumeur, P., G.D. Paterno, G. Boileau, J. Claverie, and D. Skup. 1987. Isolation and characterisation of a murine cDNA clone highly homologous to the yeast L29 ribosomal protein gene. Nucleic Acid Res. 15: 1019-1029.

Carrington, J.L., A.B. Roberts, K.C. Flanders, N.S. Roche, and A.H. Reddi. 1988. Accumulation, localization, and compartmentation of transforming growth factor $\beta$ during endochondral bone development. J. Cell Biol. 107: 1969-1975.

Cawston, T., W.A. Galloway, E. Mercer, G. Murphy, and J.J. Reynolds. 1981. Purification of rabbit bone inhibitor of collagenase. Biochem. I. 195: 159-165.

Cawston, T.E., G. Murphy, E. Mercer, W.A. Galloway, B.L. Hazleman, and J.J. Reynolds. 1983. The interaction of purified rabbit bone collagenase with purified rabbit bone metalloproteinase inhibitor. Biochem. J. 211: 313-318.

Chirgwin, J., A. Przybyla, R. MacDonald, and W. Rutter. 1979. Isolation of biologically active ribonucleic acid from sources enriched in ribonuclease. Biochemistry 18: 5294-5299.

Clark, S.D., S.M. Wilhelm, G.P. Stricklin, and H.G. Welgus. 1985. Coregulation of collagenase and collagenase inhibitor production by phorbol myristate acetate in human skin fibroblasts. Arch. Biochem. Biophys. 241: 36-44.

Coulombe, B. and D. Skup. 1988. In vitro synthesis of the active tissue inhibitor of metalloproteinases encoded by a complementary DNA from virus-infected murine fibroblasts. I. Biol. Chem. 263: 1439-1443.

Coulombe, B., A. Ponton, L. Daigneault, B.R.G. Williams, and D. Skup. 1988. Presence of transcription regulatory elements within an intron of the virus-inducible murine TIMP gene. Mol. Cell. Biol. 8: 3227-3234.

Dannenberg, A.M. and M. Suga. 1981. Histochemical stains for macrophages in cell smears and tissue sections: $\beta$-galactosidase, acid phosphatase, nonspecific esterase, succinic dehydrogenase, and cy tochrome oxidase. In Methods for studying mononuclear phagocytes (ed. D. Adams, P. Edelson, and M. Koren) pp. 375-396. Academic Press, New York.

Davis, C.A., S.E. Noble-Topham, J. Rossant, and A.L. Joyner. 1988. Expression of the homeo box-containing gene EN-2 delineates a specific region of the developing mouse brain Genes Dev. 2: $361-371$.

Dean, D.D., J. Martel-Pelletier, J. Pelletier, D.S. Howell, and J.F. Woessner, Jr. 1989. Evidence for metalloproteinase and metalloproteinase inhibitor imbalance in human osteoarthritic cartilage. J. Clin. Invest. 84: 678-685.

Dunn, J.M., R.A. Phillips, A.J. Becker, and B.L. Gallie. 1988. Identification of germline and somatic mutations affecting the retinoblastoma gene. Science 241: 1797-1800.

Edwards, D.R., G. Murphy, J.J. Reynolds, S.E. Whitham, A.J.P. Docherty, P. Angel, and J.K. Heath. 1987. Transforming growth factor beta modulates the expression of collagenase and metalloproteinase inhibitor. EMBO J. 6: 1899-1904.

Feinberg, A.P. and B. Vogelstein. 1983. A technique for radiolabeling DNA restriction endonuclease fragments to high specific activity. Anal. Biochem. 132: 6-13.

Flenniken, A.M., J. Galabru, M.N. Rutherford, A.G. Hovanessian, and B.R.G. Williams. 1988. Expression of interferoninduced genes in different tissues of mice. $J$. Virol. 62: 3077-3083.

Gewert, D.R., B. Coulombe, M. Castelino, D. Skup, and B.R.G. Williams. 1987. Characterization and expression of a murine gene homologous to human EPA/TIMP: a virus-induced gene in the mouse. EMBO J. 6: 651-657.

Gossler, A., A.L. Joyner, J. Rossant, and W.C. Skarnes. 1989. Mouse embryonic stem cells and reporter constructs to detect developmentally regulated genes. Science 244: 463465

Hall, C., P. Jacob, G. Ringold, and F. Lee. 1983. Expression and regulation of $\mathrm{E}$. coli lacZ gene fusions in mammalian cells. J. Mol. Appl. Genet. 2: 101-109.

Harris, E., H. Welgus, and S. Krane. 1984. Regulation of mammalian collagenase. Collagen Rel. Res. 4: 493-512.

Heine, U.I., E.F. Munoz, K.C. Flanders, L.R. Ellingsworth, H.Y.P. Lam, N.L. Thompson, A.B. Roberts, and M.B. Sporn. 1987. Role of transforming growth factor- $\beta$ in the development of the mouse embryo. J. Cell Biol. 105: 2861-2876.

Hogan, B., F. Costantini, and E. Lacey. 1986. Introduction of new genetic information into the developing mouse embryo. In Manipulating the mouse embryo. pp. 152-203. Cold Spring Harbor Laboratory Press, Cold Spring Harbor, New York.

Holland, P.W.H., S.J. Harper, J.H. McVey, and B.L.M. Hogan. 1987. In vivo expression of mRNA for the $\mathrm{Ca}^{++}$-binding protein SPARC (Osteonectin) revealed by in situ hybridization. J. Cell Biol. 105: 473-482.

Ignotz, R.A. and J. Massague. 1986. Transforming growth factor- $\beta$ stimulates the expression of fibronectin and collagen and their incorporation into the extracellular matrix. J. Biol. Chem. 261: 4337-4345.

Kothary, R., S. Clapoff, S. Darling, M.D. Perry, L.A. Moran, and J. Rossant. 1989. Inducible expression of an hsp68-lacZ hybrid gene in transgenic mice. Development 105: 707-714.

Leeson, C.R., T.S. Leeson, and A.A. Paparo. 1985. The digestive system. In Textbook of histology, pp. 317-326. W.B. Saunders Co., Toronto.

Lehnert, S.A. and R.J. Akhurst. 1988. Embryonic expression pattern of TGF beta type-1 RNA suggests both paracrine and autocrine mechanisms of action. Development 104: 263273.

Maniatis, T., E.F. Fritsch, and J. Sambrook. 1982. Molecular cloning: a laboratory manual. Cold Spring Harbor Laboratory Press, Cold Spring Harbor, New York.

McGee-Russell, S.M. 1958. Histochemical methods for calcium. J. Histochem. 6: 22-42. 
Melton, D., D. Krieg, M. Rebagliati, T. Maniatis, K. Zinn, and M. Green. 1984. Efficient in vitro synthesis of biologically active RNA and RNA hybridization probes from plasmids containing a bacteriophage SP6 promoter. Nucleic Acid Res. 12: $7035-7056$.

Mignatti, P., E. Robbins, and D. Rifkin. 1986. Tumor invasion through the human amniotic membrane: requirement for a proteinase cascade. Cell 47: 487-498.

Mullins, L.J., S.G. Grant, D.A. Stephenson, and V.M. Chapman. 1988. Multilocus molecular mapping of the mouse X chromosome. Genomics 3: 187-194.

Murphy, G. and J.J. Reynolds. 1985. Current views of collagen degradation. BioEssays 2: 55-60.

Murphy, G., J.J. Reynolds, and Z. Werb. 1985. Biosynthesis of tissue inhibitor of metalloproteinases by human fibroblasts in culture. J. Biol. Chem. 260: 3079-3083.

Nomura, S., B.L.M. Hogan, A.J. Wills, J.K. Heath, and D.R. Edwards. 1989. Developmental expression of tissue inhibitor of metalloproteinase (TIMP) RNA. Development 105: 575583.

Overall, C.M., J.L. Wrana, and J. Sodek. 1989. Independent regulation of collagenase, $72-\mathrm{kDa}$ progelantinase, and metalloendoproteinase inhibitor expression in human fibroblasts by transforming growth factor- $\beta$. J. Biol. Chem. 264: 18601869.

Pelton, R.W., S. Nomura, H.L. Moses, and B.L.M. Hogan. 1989. Expression of transforming growth factor $\beta 2$ RNA during murine embryogenesis. Development 106: 759-767.

Rugh, R. 1968. The mouse: its reproduction and development. Burgess Publishing Co., Minneapolis.

Sakyo, K., A. Ito, C. Ogawa, and Y. Mori. 1986. Hormonal control of collagenase inhibitor production in rabbit uterine cervical fibroblast-like cells. Biochim. Biophys. Acta 883: $517-522$.

Sandberg, M., T. Vuorio, H. Hirvonen, K. Alitalo, and E. Vuorio. 1988. Enhanced expression of TGF- $\beta$ and $c-f o s$ mRNAs in the growth plates of developing human long bones. Development 102:461-470.

Southern, E. 1975. Detection of specific sequences among DNA fragments separated by gel electrophoresis. I. Mol. Biol. 98: $503-517$.

Tryggvason, K., M. Hoyhtya, and T. Salo. 1987. Proteolytic degradation of extracellular matrix in tumour invasion. Biochim. Biophys. Acta 907: 191-217.

Welgus, J. and G. Stricklin. 1983. Human skin fibroblast collagenase inhibitor. J. Biol. Chem. 258: 12259-12264.

Welgus, J., J. Jeffrey, A. Eisen, W. Roswit, and G. Stricklin. 1985. Human skin fibroblast collagenase: interaction with substrate and inhibitor. Collagen Rel. Res. 5: 167-179.

Willard, H.F., S.J. Durfy, M.M. Mahtani, H. Dorkins, K.E. Davies, and B.R.G. Williams. 1989. Regional localization of the TIMP gene on the human X chromosome. Hum. Genet. 81: 234-238. 


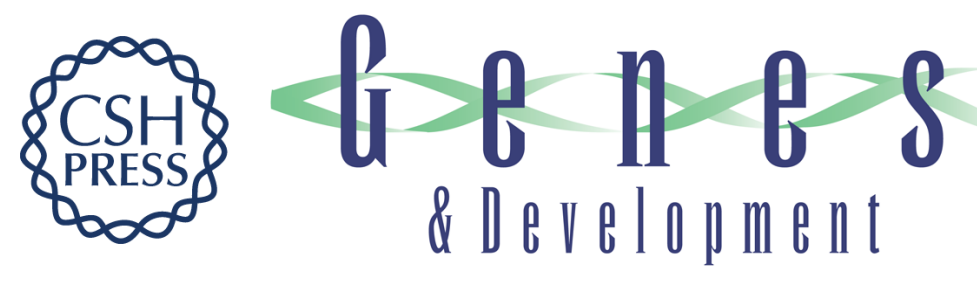

\section{Developmental expression of the endogenous TIMP gene and a TIMP-lacZ fusion gene in transgenic mice.}

A M Flenniken and B R Williams

Genes Dev. 1990, 4:

Access the most recent version at doi:10.1101/gad.4.7.1094

References This article cites 39 articles, 20 of which can be accessed free at: http://genesdev.cshlp.org/content/4/7/1094.full.html\#ref-list-1

License

Email Alerting

Service

Receive free email alerts when new articles cite this article - sign up in the box at the top right corner of the article or click here.

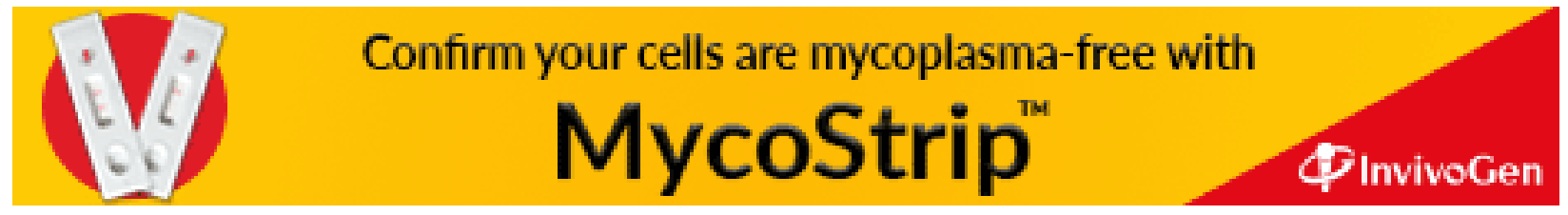

